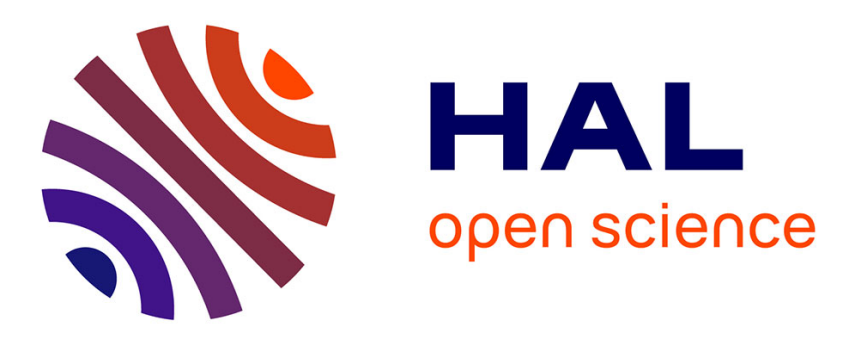

\title{
Stress response varies with plumage colour and local habitat in feral pigeons
}

Hélène Corbel, Ariane Legros, Claudy Haussy, Lisa Jacquin, Julien Gasparini, Battle Karimi, Adrien Frantz

\section{- To cite this version:}

Hélène Corbel, Ariane Legros, Claudy Haussy, Lisa Jacquin, Julien Gasparini, et al.. Stress response varies with plumage colour and local habitat in feral pigeons. Journal für Ornithologie = Journal of Ornithology, 2016, 157 (3), pp.825-837. 10.1007/s10336-016-1331-9 . hal-01332577

\section{HAL Id: hal-01332577 \\ https://hal.sorbonne-universite.fr/hal-01332577}

Submitted on 16 Jun 2016

HAL is a multi-disciplinary open access archive for the deposit and dissemination of scientific research documents, whether they are published or not. The documents may come from teaching and research institutions in France or abroad, or from public or private research centers.
L'archive ouverte pluridisciplinaire HAL, est destinée au dépôt et à la diffusion de documents scientifiques de niveau recherche, publiés ou non, émanant des établissements d'enseignement et de recherche français ou étrangers, des laboratoires publics ou privés. 
$3{\text { Hélène } \text { Corbel }^{\mathrm{a}} \text {, Ariane Legros }}^{\mathrm{a}}$, Claudy Haussy ${ }^{\mathrm{a}}$, Lisa Jacquin ${ }^{\mathrm{a}, \mathrm{b}}$, Julien Gasparini ${ }^{\mathrm{a}}$, Battle 4 Karimi $^{\mathrm{a}}$ \& Adrien Frantz* ${ }^{\mathrm{a}}$

5

$6{ }^{a}$ Sorbonne Universités, UPMC Univ Paris 06, UPEC, Paris 7, CNRS, INRA, IRD, Institut 7 d'Ecologie et des Sciences de l'Environnement de Paris, F-75005, Paris, France

8 b Univ. Toulouse 3 Paul Sabatier, CNRS, ENFA, UMR 5174 EDB (Laboratoire Evolution and 9 Diversité Biologique), FR-31062 Toulouse, France

10

*Corresponding author:

Dr. Adrien FRANTZ

Institute of Ecology and Environmental Sciences - Paris

7, quai Saint-Bernard - Bât. A 7ème étage (Case 237)

F-75252 Paris cedex 05

adrien.frantz@upmc.fr

Telephone number: +33144273823

Fax number: +33144273516

\section{Running title: colouration and stress response in feral pigeons}




\section{Abstract}

Bird populations exposed to different extrinsic conditions often differ in the responsiveness of the hypothalamo-pitituary-adrenal (HPA) axis and thus in corticosterone response that individuals mount when facing stressful events. However, the contribution of genetic variation to among-individual variability in HPA axis responsiveness across different environmental conditions is poorly understood. Melanin-based coloured types provide reliable phenotypic markers of alternative genotypes underlying stress coping styles. Large variations in melanin-based colouration are heritable in feral pigeons. We tested whether melanin-based colouration is associated with variation in corticosterone stress response in feral pigeons. To this aim, we examined how corticosterone response varies both within and between differently coloured individuals across different environmental conditions. Differently coloured individuals mounted different stress-induced corticosterone levels in interaction with environmental conditions: dark pigeons exhibited a higher corticosterone when originating from rural habitats, while such relation was not observed in pale pigeons. This suggests that among-population variation in stress response is higher in dark pigeons, this variation possibly reflecting adjustment and/or (epi)genetic adaptation to environmental conditions. In addition, corticosterone response increased with the degree of melanin-based colouration in pigeons originating from rural habitats but not in pigeons originating from more urbanized populations, resulting in the coexistence of alternative stress responses in some populations, but not in others. Our results suggest that species with melanin-based variation in differently 
urbanized populations along rural-urban gradient are potentially good candidate systems for studying stress coping styles under alternative selective regimes.

Key-words: glucocorticoids, inter-individual variations, local adaptation, phenotypic flexibility, phenotypic plasticity, pigmentation, restraint stress, urbanization

\section{Introduction}

When facing unpredictable and threatening events due to biotic or abiotic factors, vertebrates mount a stress response which helps individuals to meet energetic demands through resource allocation trade-offs. The hypothalamo-pitituary-adrenal (HPA) axis which culminates in the release of glucocorticoids (GC) is one of the most important physiological mediators of stress response. Thus, stress-induced increases in GC concentrations redirect behaviour and physiology towards immediate survival functions through neoglucogenesis, an increase in locomotor activity and the inhibition of non-vital functions such as reproduction (Dhabhar \& McEwen 1997; Breuner et al. 1998; Sapolsky et al. 2000). Due to its broad implication in the trade-off between survival and reproduction, the HPA-axis reactivity is closely related to fitness (Breuner et al. 2008 ; Crespi et al. 2013). Hence the adaptive function of the HPA-axis is pervasively invoked to explain differences in stress-induced GC concentrations between populations or subspecies exposed to different extrinsic conditions, with a heavy bias towards bird studies (e.g. altitude: Addis et al. 2011; habitat quality: Busch \& Hayward 2009; predation risk: Thiel et al. 2008; urbanization level: Parteke 2006). Indeed, rising GC stress response could facilitate a fast recovery of positive energy balance in contexts of great energetic demands and low energy stores (McEwen \& Wingfield 2003; Addis et al. 2011) whereas lowering the response reduces the negative impacts of chronically elevated GC on non-vital functions (e.g. immunity and resistance to oxidative stress; Stier et al. 2009; Silverin 
1998). For instance, up- or down-modulations of stress response would be of primary importance for all animals copying with frequent anthropogenic disturbances (Partecke, 2006), possibly facilitating the expansion of species ranges in novel urban environments as suggested by persistent differences detected in GC responses between recently urbanized populations of dark-eyed juncos Junco hyemalis and wildland populations in the ancestral range (Atwell et al. 2012).

Comparing bird populations or subspecies, what drives differences in the HPA stress response remains unclear. On one hand, such differences may arise because populations or subspecies adjust stress response to the prevailing conditions that birds experience at the time of sampling. Indeed, the HPA-axis activity is highly flexible to e.g. food availability (Schoech 2006; Schoech et al. 2007) or human disturbances (Cockrem et al. 2006). The HPA-axis activity also varies as a function of internal state, e.g. body condition (Corbel et al. 2010) or stage of life cycle (Romero 2002). On the other hand, stable differences between populations may result from differential selective pressures favouring individuals with respective specific corticosterone stress response through fitness consequences (Satterlee \& Johnson 1988; Evans et al. 2006; Wada et al. 2009; Almasi et al. 2010). Indeed, inter-individual variation in the magnitude of elevated GC concentrations is repeatable and partly under genetic control (Evans et al. 2006; Partecke et al. 2006; Rensel \& Schoech 2011; Jenkins et al. 2014). The heritability of the GC response to stress is supported by cross-fostering experiments in the field (Jenkins et al. 2014) and by selection studies in captive settings (Evans et al. 2006 ; Satterlee \& Johnson 1988), which confirm that individual variation in GC stress response is underlaid by an appreciable amount of standing additive genetic variation. Stable differences may also arise because of environmental factors that have affected the development of the HPA axis during early life and, thus, the GC stress response that adults can mount (Love \& Williams 2008a; Love \& Williams 2008b; Wada et al. 2009). Thus, the degree to which 
phenotypic adjustments to environmental stimuli and genetic differences resulting from local adaptation underlie between-population differences in stress response is often unclear while the interplay of both processes is likely to be significant. The maintenance of different populations in common conditions is the first step for disentangling acute adjustments from more stable, possibly genetically-determined, divergences in the HPA-axis reactivity (Angelier et al. 2011; Atwell et al. 2012). To have a full view about the regulation of active blood circulating corticosterone, we should also consider the regulation of CBG and hence of free corticosterone and corticosterone bound to CBG (Almasi et al. 2009).

Large variations in the magnitude of GC response to stress also occur within populations with some individuals having constantly low or constantly high GC responses across time, together with a suite of correlated behavioural and physiological traits, leading to distinct, repeatable stress copying styles (Cockrem 2007; Cockrem et al. 2009; Koolhass et al. 1999). Genetic studies using offspring-parent regression found significant narrow-sense heritability estimates of coping styles $(25 \%$, Drent et al. $2003 ; 22 \%$ : Dingemanse et al. 2002 ; reviewed in van Oers et al. 2005). Stress-coping styles define coherent sets of behavioural and physiological responses, including corticosterone release, to challenges faced by animals (Koolhaas et al. 1999). Based on the empirical findings that different coping styles influence fitness parameters (Dingemanse et al. 2003; Dingemanse et al. 2004), individual variations in stress responses may have major eco-evolutionary implications and consequences (Wolf \& Weissing 2012). First, the coexistence of coping styles occurs only under certain selective regimes, presumably involving fluctuating and/or frequency-dependent selective pressures (Carere et al. 2010; Wolf \& McNamara 2012). Second, the potential for evolvability in response to new selective regimes should be particularly high for populations with genetic differences in copying styles (Wolf \& Weissing 2012). Thus, the consideration of among- 
individual variation while comparing stress response between populations is crucial, although largely overlooked (Williams et al. 2008; but see Atwell et al. 2012).

Interestingly, melanin-based coloured morphs provide reliable phenotypic markers of alternative genotypes (Theron et al. 2001; Mundy et al. 2004) that are associated with stress coping styles in several taxa (Ducrest et al. 2008; Almasi et al. 2010; Kittilsen et al. 2009). This is thought to be due to the pleiotropic effects that the genes coding for the melanocortin system exert on stress response (Daynes et al. 1987; Racca et al. 2005) and suites of correlated phenotypic traits (e.g. aggressiveness, Ducrest et al. 2008, Morgan et al. 2004). Accordingly, differently coloured individuals differently regulate the HPA axis as reflected by different stress-induced GC levels, the association between colouration and stress response being heritable (Almasi et al. 2010). In addition, facing varying levels of stress, differently coloured individuals display alternative reaction norms on energy balance and trade-offs between competing physiological functions (Dreiss et al. 2010; Jacquin et al. 2012) as expected if stress response is colour-specific. However, whether direction and/or magnitude of the covariation between stress-induced GC levels and plumage colouration differs between different populations living in different environmental conditions has not been tested yet.

In this study, we investigated stress response in the feral pigeon Columba livia. Feral pigeons originate from domestic pigeons and artificially-selected variation in melanin-based colouration persists in feral populations (Johnston \& Janiga 1995; Sol 2008). Such variation in colouration is heritable and associated with alternative physiological norms of reaction as also found in other species with plumage colour variation (Jacquin et al. 2012; Jacquin et al. 2013). After escaping from captivity in the early XIX ${ }^{\text {th }}$ century, pigeons have established in a variety of habitats and undergone natural selection ever since (Johnston \& Janiga 1995; Sol 2008). Habitats of feral pigeons markedly differ notably in their level of urbanization, ranging from rural areas to city centers. Because urbanization dramatically affects both abiotic and 
biotic environmental conditions (e.g. climate, human disturbance, population density, resource availability, predation risk; Shochat et al. 2006; McDonnell \& Hahs 2009; Niemela et al. 2011), it can alter selection on morphological, behavioral, and physiological traits (Liker et al. 2008; Møller 2008; Jacquin et al. 2013; Atwell et al. 2012), including stress response (e.g. Partecke et al. 2006). Accordingly, differences in stress response between differently urbanized populations have been shown in several bird species (reviewed in Bonier 2012), however we crucially lack information on how this trait varies across rural-urban gradients (but see Atwell et al. 2012). A noticeable effect of human activities is the buffering of temporal changes in environmental conditions notably for those species relying on humans for food resources as is the case in feral pigeons (Johnston \& Janiga 1995; Shochat 2006). Because instability of environment is a potent selective mechanism explaining the maintenance of distinct stress copying styles within populations (Carere et al. 2010), the magnitude of among-individual variation in stress response can be hypothesized to vary along a rural-urban gradient, being lower in more stable, urban habitat. In this study, we tested whether the variation in melanin-based colouration was related to pigeons, we expected differently coloured feral pigeons to display alternative stress responses. alternative stress responses in feral pigeons. To this aim, we examined how stress responses varies both within and between differently coloured individuals in differently urbanized populations. We maintained wild feral pigeons captured in three differently urbanized habitats in similar environmental conditions to disentangle immediate phenotypic adjustments from more stable divergences in the HPA-axis activity (Angelier et al. 2011). Captive feral pigeons were submitted to a standard acute restraint stress to compare their corticosterone (main avian GC) response. If melanin-based colouration is a phenotypic marker of stress responses in feral Furthermore, if differently coloured feral pigeons display alternative stress responses depending on their originating population, we expected differently coloured individuals to 
mount different stress-induced corticosterone levels in interaction with habitat. In addition, we expected to detect lower differences in corticosterone stress response between differently coloured pigeons in those populations thriving with more stable environmental conditions as found in urban centers.

\section{Materials and methods}

Capture and experiments were all approved by the Direction Départementale des Services Vétérinaires de Seine-et-Marne (activity permit \# 77-06; aviary licence \# A77-431-1).

\section{Capture}

Feral adult pigeons were caught with trap cages at the beginning of February 2010 in three different habitats (Urban center, $\mathrm{n}=25$ individuals; Urban park, $\mathrm{n}=22$ individuals; Rural farm, $\mathrm{n}=24$ individuals) of the Parisian region (Table 1). Urban park and center were located in the city of Paris. The farm was situated in a rural area in the Parisian suburbs. Because the distance between capture sites was higher than the recently estimated distance covered by the Parisian feral pigeons within their local environment (less than 800 m; Frantz et al. 2012), we assume that these 3 habitats reflect distinct populations with restricted movements between them, thus experiencing different local environmental conditions which can be described as rural farm, urban park and urban center. Urbanization rate of each site was estimated using land use inventory for Paris area (MOS 2003, Institut d'Aménagement et d’Urbanisme Ile-deFrance) and MapInfo Professional 8.5 SCP (Pitney Bowes Software Inc.). It was calculated as the proportion of area covered by buildings and roads on the total circular area within a radius of $1000 \mathrm{~m}$ around the capture site (Jacquin et al. 2013b; Table 1).

\section{Melanin-based colouration}

Feral pigeons display a continuous variation in melanin-based plumage colouration from entirely white to entirely black (Johnston \& Janiga 1995). The continuous variation of the 
surface of dark area on the wings across colouration patterns corresponds to different levels of melanin deposited in feathers (Haase et al., 1992; Jacquin et al., 2011). Melanin-based colouration was assessed following Jacquin et al. (2011) using pictures of the upper wing taken in standardized light conditions. Ligh conditions were standardized by the use of a $1 \mathrm{~m}^{2}$ reflecting white sheet placed $50 \mathrm{~cm}$ in the background of the wing, and of two studio lamps placed $1 \mathrm{~m}$ both at the left and the right sides from the wing. The wing was stretched by an experimenter and pictures were taken at a resolution of 96 DPI using a camera (Sony DSCHX1) placed on tripod $1 \mathrm{~m}$ from the wing, being saved under JPG files. Pictures were binary transformed using Gimp (GNU image manipulation program) and colouration score was determined as the proportion of black pixels (\%) on the upper wing using ImageJ (U.S. National Institutes of Health, Bethesda, USA). For analyses purposes, pale and dark colour groups were defined as pigeons with colouration scores $<50 \%$ and $>50 \%$ respectively (Jacquin et al. 2013a). This colouration score has been shown to be highly heritable (82\%; Jacquin et al. 2013a).

\section{Housing}

Immediately after capture, body mass was measured using a Pesola spring balance $( \pm 5 \mathrm{~g})$ and pigeons were brought to the Centre de Recherche en Ecologie Expérimentale et Prédictive (CEREEP, Saint-Pierre-lès-Nemours, France). Pigeons from each habitat were kept in separate outdoor aviaries to limit social and physiological perturbations. Indeed, behavioural and immune traits such as aggressiveness levels and parasite loads often differ between differently urbanized bird populations (e.g. Evans 2010; Jacquin et al. 2013b). Thus mixing pigeons from different origins would potentially have confounded the results as both social and parasite environments impact individual corticosterone release in birds (Raouf et al. 2006; Pryke et al. 2007). In addition, social interactions among different colour morphs can generate frequency-dependent effects in the local environment, which may directly affect the 
level of stress captive birds are exposed to (Pryke et al. 2007; Morgan et al. 2004). In this study, colouration scores were similarly distributed among the different aviaries (Median test: $\chi_{2}^{2}=4.909, \mathrm{P}=0.086 ;$ Kruskal Wallis test: $\left.\mathrm{H}=3.671, \mathrm{df}=2, \mathrm{P}=0.160\right)$ and median score was close to $50 \%(48.7 \%)$, thus any frequency-dependent effect of differently coloured individuals within aviaries on individual corticosterone release was very unlikely. Aviaries were strictly identical $(3.10 \mathrm{~m} \times 2 \mathrm{~m} \times 2.40 \mathrm{~m})$, adjacent and visually isolated from one another to limit perturbations. Water and maintenance diet (a mixture of peas, corn and maize) were provided ad libitum. This design allowed keeping pigeons in similar captive conditions in terms of housing conditions, bird density and exposure to external stressors. Pigeons were acclimatized to captivity for at least three weeks before measuring their stress responses until daily food intake and body weight were stabilized (Pascual et al. 1999). At the end of the acclimation period, body mass varied by only $2.2 \pm 0.5 \%(n=71)$ from the values at capture, this variation being four-fold lower than that associated with an alteration of the HPA function in captive birds ( > 8\%, Romero et al. 1997; Romero \& Wingfield 1999; Dickens et al. 2009). Mass changes during acclimation were not affected by pigeon origin $\left(F_{2,68}=1.319, P=0.274\right)$, colour type $\left(F_{1,69}=0.005, P=0.942\right)$ or the interaction between both $\left(F_{2,65}=1.306, P=0.278\right)$.

\section{Stress response measurement}

At the end of the acclimation period, all pigeons were subjected to a standard acute restraint stress following a modified version of a protocol by Romero \& Wingfield (2001). Experiments were done from the end of February to mid-March 2010 between 9:00 h and 13:00 $\mathrm{h}$ to minimize the effects of seasonal and circadian changes in corticosterone plasma

240 levels, respectively (Breuner et al., 1999; Romero 2002). The time of day was not related to baseline levels of corticosterone $\left(\mathrm{R}^{2}=0.001, \mathrm{P}=0.845, \mathrm{~N}=41\right)$ however it was weakly but significantly related to the levels of stress-induced corticosterone $\left(\mathrm{R}^{2}=0.096, \mathrm{P},=0.049 \mathrm{~N}=\right.$ 
41). Because neither did the time of day differ between the aviaries $\left(\mathrm{F}_{2,38}=1.860, \mathrm{P}=0.170\right)$ nor was it related to colouration scores $\left(\mathrm{R}^{2}=0.0003, \mathrm{P}=0.918, \mathrm{~N}=41\right)$, we feel confident that the time of day did not interact with the outcomes of this study. Each pigeon was stressed only once, and a single intervention was done per day and per aviary in order to avoid physiological habituation to stress created by human intervention as demonstrated in chronically stressed birds (Cyr \& Romero 2009). Within each aviary, pigeons were randomly sampled with respect to colour type. A rapid screening of feathers was done to ensure that no bird was engaged in moult process as feather renewal may affect the HPA-axis activity (Romero 2002). The onset of the stress was considered as the time at which pigeons detected our presence nearby the aviary, usually $15 \mathrm{~s}$ before capture. Pigeons were captured with a net and thereafter kept motionless in an opaque cloth bag in order to create a restraint, stressful condition (Romero \& Wingfield 2001). At different times along the restraint stress, blood samples of $0.5 \mathrm{ml}$ were taken from the brachial vein, using a $26 \mathrm{~g}$ needle and a $1 \mathrm{ml}$ heparinized syringe. A total of $13 \%$ of blood samples, corresponding to 30 pigeons could not be used because of hemolysis or insufficient volume. Thus, analyses hereafter in this study were done on 41 pigeons. Blood was first collected at 3 min after the onset of stress (mean value: $3.30 \pm 0.10 \mathrm{~min}, n=41)$. These samples were expected to provide baseline corticosterone levels, since increase in corticosterone levels generally does not occur within 3 min following initiation of a stressful stimulus (Wingfield et al. 1982). Subsequent samples were collected at $10 \mathrm{~min}$ (mean value: $10.71 \pm 0.41 \mathrm{~min}, n=41$ ), $20 \mathrm{~min}$ (mean value: 20.46 $\pm 0.20 \mathrm{~min}, n=41)$ and $30 \mathrm{~min}$ (mean value: $29.89 \pm 0.10 \mathrm{~min}, n=41$ ) after the onset of stress, to obtain a time course of the stress response (Romero \& Wingfield 2001). Total blood volume collected from any individual did not exceed $2 \mathrm{ml}$ i.e. less than $1 \%$ of body mass as recommended by McGuill \& Rowan (1989). Immediately after restraint, pigeons were weighed to the nearest $5 \mathrm{~g}$. Body mass at restraint was similar between individuals displaying 
alternative colour types $\left(F_{1,39}=1.304, P=0.260\right)$ or from different habitats $\left(F_{2,38}=0.670, P=\right.$ 0.517 ) as this was also the case for body mass at capture (colour type effect: $F_{1,39}=0.951, P=$ 0.336; habitat effect: $\left.F_{2,38}=0.958, P=0.393\right)$. Finally, a blood smear was taken to determine parasite intensity (Haemoproteus spp.) as the number of infected red blood cells among 10 000 cells from different microscopic fields forming a monolayer (Sol et al. 2000; Jacquin et al. 2011). Parasite intensity did not vary between colour types $\left(F_{1,39}=2.002, P=0.165\right)$ or habitats $\left(F_{2,38}=0.625, P=0.541\right)$. Blood samples were immediately centrifuged for 10 minutes at $14000 \mathrm{rpm}$ to separate plasma from red blood cells. Plasma were then kept at $-20^{\circ}$

C until corticosterone analyses (see below). Red blood cells were kept in a PBS/EDTA anticoagulant solution and were used for molecular sex determination. Briefly, DNA was extracted using a Qiagen kit (DNeasy Blood and Tissue kit, cat. 69506, Qiagen Sciences) and amplified by polymerase chain reaction using the P8 and P2 primers following Griffiths et al. (1998). Sex ratio did not differ significantly for pale and dark pigeons $\left(\chi_{1}^{2}=0.028, P=0.867\right)$ and for different habitat types $\left(\chi_{2}^{2}=0.196, P=0.907\right)$. Because the HPA axis activity is likely to be influenced by body mass, parasite intensity and sex (e.g. O'Reilly \& Wingfield 2001; Cockrem et al. 2006; Raouf et al. 2006), all these factors were included in the model explaining the variation in corticosterone levels along restraint stress (see below).

\section{Corticosterone levels measurement}

Plasma corticosterone concentrations were determined with an enzyme-immunoassay procedure (corticosterone EIA kit, cat. AC-14F1, IDS Ltd) using polyclonal antiserum against corticosterone coated onto the inner surface of polystyrene microtitre wells. Calibrators, controls and diluted (1:2) plasma samples were incubated overnight at $28{ }^{\circ} \mathrm{C}$ with peroxidaselabeled corticosterone in the antibody-coated wells. Wells were then washed and a colour reaction was developed using the tetramethylbenzidine chromogen. The absorbance of the reaction mixtures was read in a microplate reader. Colour intensity developed is inversely 
proportional to the concentration of corticosterone in the diluted samples. The sensitivity of assays was $0.55 \mathrm{ng} . \mathrm{ml}^{-1}$ and intra- and inter-assay repeatability were $87.4 \%$ and $79.4 \%$, respectively.

\section{Statistical analyses}

The aim of this study was to investigate the interacting effect of melanin-based colouration with habitat on corticosterone levels. To do this, we used general linear mixed models with corticosterone levels as the dependent variable, blood sampling time along with restraint (i.e. the time since the onset of stress), habitat, colour type (pale and dark pigeons) and their interactions as fixed factors, and individual nested within habitat as a random factor. Sex, body mass and parasite intensity were also added as covariates in the model. The best model was chosen according to the $\mathrm{AIC}_{\mathrm{C}}$ criterion (Burnham \& Anderson 2002) using a descending model selection procedure starting with a model containing the following predictor variables: time, habitat, colour type and all second- and three-term associated interactions plus sex, body mass and parasite intensity. When an interaction was significant, we conducted post-hoc pairwise t-tests using a Bonferroni correction applied on $\alpha$ level of significance for the $\mathrm{t}$ statistic computed by Fishers's LSD method, to control for multiple comparisons of corticosterone levels. $P$-values were adjusted so that a significant level of 0.05 was consistently used (see below). The interacting effect of colour type with habitat on corticosterone levels (see results) was further examined by separate analyses of regression of stress-induced corticosterone levels on colouration scores (continuous variable) in pigeons from each origin. All analyses were run under SPSS 20.0.0. Significance levels were set to 0.05 and tests were two-tailed. Means are computed with their standard errors. 
Corticosterone levels increased from $2.07 \pm 0.16 \mathrm{ng} \cdot \mathrm{ml}^{-1}$ (at $3 \mathrm{~min}$ after capture) to $14.27 \pm$ $1.38 \mathrm{ng} \cdot \mathrm{ml}^{-1}$ (at $30 \mathrm{~min}$ after capture; $n=41, F_{3,120}=63.422, P<0.001$ ) across successive blood sampling times, showing that restraint induced a significant stress in individuals. Corticosterone levels measured at 30 minutes after capture were significantly higher than baselines in all groups of pigeons as defined by each combination of colouration $\times$ habitat levels (Bonferroni correction, all $P \leq 0.012$ ).

Changes in corticosterone across blood sampling times was significantly associated with the interacting effect of colour type with habitat, as resulting from the best model (effect of Sampling time $\mathrm{x}$ Colour type $\mathrm{x}$ Habitat: $P=0.03, \mathrm{AIC}_{\mathrm{C}}=884.31$; Table 2). Corticosterone levels measured in restrained individuals at $3 \mathrm{~min}$ and at $10 \mathrm{~min}$ after capture were neither associated with colour type (post hoc Bonferroni correction, all $P>0.473$ ) nor with habitat (post hoc Bonferroni correction, all $P>0.999$, Figure 1). By contrast, at $20 \mathrm{~min}$ and at $30 \mathrm{~min}$ after capture, darker individuals reached significantly higher corticosterone levels than paler individuals, this difference being detected in pigeons from rural habitat (post-hoc Bonferroni correction, at $20 \mathrm{~min}: P=0.01$; at $30 \mathrm{~min}: P<0.001$; Figure 1), but not in pigeons from other habitats (post hoc Bonferroni correction, at $20 \mathrm{~min}$ : all $P>0.37$; at $30 \mathrm{~min}:$ all $P>$ 0.08; Figure 1). In addition, corticosterone levels measured at $20 \mathrm{~min}$ and at $30 \mathrm{~min}$ after capture significantly differed among habitats, being higher in pigeons from the rural habitat than in pigeons from the urban center habitat, these differences being detected in darker individuals (post hoc Bonferroni correction for urban center versus rural farm at 20 min: $P=$ 0.046; at 30 min: $P<0.001$; Figure 1), but not in paler individuals (post-hoc Bonferroni at 20 min: all $P>0.93$; at 30 min: all $P>0.67$; Figure 1). A positive, linear relation between stressinduced corticosterone levels at $30 \mathrm{~min}$ and colouration scores (continuous variable) was detected in pigeons from rural farm $\left(F_{1,11}=7.190, P=0.021, R^{2}=0.395, n=13\right.$; Figure $\left.2 \mathrm{c}\right)$ suggesting than darker pigeons mounted a stronger corticosterone response, but not in pigeons 
343 from urban center $\left(F_{1,13}=1.773, P=0.206, R^{2}=0.120, n=15\right.$; Figure 2a $)$ or urban park $\left(F_{1,11}\right.$

$344=1.094, P=0.318, R^{2}=0.090, n=13$; Figure 2b).

\section{Discussion}

348 The aim of this study was to compare stress response both within and between differently 349 coloured pigeons across differently urbanized habitats.

Our results show that dark pigeons from the rural habitat reached higher levels of corticosterone levels in response to stress as compared to dark pigeons from the urban center habitat and to pale pigeons from either habitat. Differences between mean corticosterone levels at $30 \mathrm{~min}$ of restraint that are necessary for statistical tests to have an acceptable power $(80 \%)$ have been defined by a recent meta-analysis using the coefficients of variation obtained in several bird species (Cockrem et al. 2009). A rule of thumb is that the difference between means must be at least $80 \%$ and $50 \%$ of the lowest mean for sample sizes of 5 and 10 , respectively. In this study, mean corticosterone levels at 30 min differed by $143 \%$ and $137 \%$ of the lowest mean between differently coloured pigeons in rural habitat $\left(9.80\right.$ ng.ml ${ }^{-1}$ versus 23.21 ng. $\mathrm{ml}^{-1}, \mathrm{~N}>6$ ) and between dark pigeons from differently urbanized habitats (9.55 ng. $\mathrm{ml}^{-1}$ versus 23.21 ng. $\mathrm{ml}^{-1}, \mathrm{~N} \geq 5$ ), respectively. Thus, we were confident that the significant interacting effect of colour type with habitat on stress-induced corticosterone levels did not arise by sampling error.

Inter-individual variations in corticosterone stress response can arise from altered pituitary and/or adrenal functions due to chronic stress generated by captive (Romero \& Wingfield 1999; Dickens et al. 2009) or natural conditions (Walker et al. 2006; Cyr \& Romero 2009), but this possibility seems unlikely in our study. First, acclimation to captivity lasted for at least three weeks (following Pascual et al. 1999) and resulted in low body mass variation (2 
$\%$ only) and in corticosterone levels close to, or lower than, those of free-living pigeons (baseline levels: 2 versus 9 ng. $\mathrm{ml}^{-1}$; stress-induced levels; 14 versus 15 ng. $\mathrm{ml}^{-1}$; Romero \& Wingfield 2001). This contrasts with expectations under stressful captive conditions (Romero et al. 1997; Romero \& Wingfield 1999; Dickens et al. 2009). Second, corticosterone baseline levels did not depend on the factors of interest (colour types and habitats; Figure 1), suggesting that different stress responses to restraint experiment were not due to differences in physiological adjustments to captivity. Additionally, it is very unlikely that any seasonal flexibility of stress response can account for differences in corticosterone levels found in our work because pigeons were all synchronized for moult and were all submitted to the same light, climate and feeding conditions. Finally, health parameters known to be affected by chronic stress (body mass and parasite intensity; Cyr \& Romero 2009) did not vary according to colour types or habitats, nor did they contribute to predict variations in corticosterone levels. Hence, variations in stress responses observed between pigeons in our study were unlikely to result from chronic stress or associated alteration of the HPA-axis.

Although we found no significant difference in health marks of chronic stress between differently coloured pigeons, the role for other physiological factors e.g. oxidative stress and/or social factors affecting corticosterone levels can not be ruled out (Senar 1999; Giraudau \& McGraw 2014). Alternatively, the difference in stress response may rather have a genetic basis. Such association between colouration and stress response may be due to the pleiotropic effects of the melanocortin system (Ducrest et al. 2008). Melanocortins ( $\alpha-, \beta-$, and $\gamma$-MSH and $\mathrm{ACTH})$ of $P O M C$-gene bind to the melanocortin-1 receptor (MC1-R) thereby triggering melanin synthesis, but also to other receptors involved in the HPA-axis activation (MC2-R and MC4-R), thus inducing some pleiotropic effects on glucocorticoid production and resistance to stress (reviewed in Ducrest et al. 2008). Accordingly, systemic injections of $\alpha-\mathrm{MSH}$ in rodents induce changes in stress-induced corticosterone levels (Daynes et al. 1987; 
Racca et al. 2005). In wild barn owls Tyto alba, genetic association between colouration and stress response has been inferred from parent-to-offspring inheritance of covariation between the degree of melanic colouration and stress-induced corticosterone levels (Almasi et al. 2010). Furthermore, in domestic rainbow trout Oncorhynchus mykiss, melanin pigmentation patterns are associated with, and can be artificially co-selected with, the responsiveness of the hypothalamus-pituitary-interrenal axis (the equivalent of HPA axis in fishes; Kittilsen et al. 2009). Here, we found that stress-induced corticosterone levels covaried with the degree of melanic colouration, as reflected by black colouration scores, in one population of feral pigeons. In the same species, food restriction affects the physiological trade-offs between maintenance and reproduction as a function of black colouration scores in the same species Indeed, under food restriction, darker eumelanic females had a higher egg production, but darker adults tended to lose more body mass than paler conspecifics (Jacquin et al. 2012). Because the HPA-axis is broadly implicated in such trade-offs (Sapolsky et al. 2000), it is likely that a responsiveness of the HPA-axis to nutritional stress depending on plumage colouration partly explains the results of Jacquin et al. 2012., which is in full accordance our results. Overall, our results support the idea that melanin-based colouration is associated with the ability to cope with stress (Fargallo et al. 2007; Roulin et al. 2008; Almasi et al. 2012) through a differential regulation of corticosterone release (Almasi et al. 2010).

The effect of origin on the covariation between colouration and stress response could reflect either an aviary effect, although the aviaries did not differ in any characteristics (size or any biotic or abiotic parameter measured), and/or a habitat effect. The effect of origin on the covariation between colouration and stress response could reflect either an aviary effect or a habitat effect, as our design could not disentangle these factors. While the first possibility cannot be ruled out, it seems unlikely because aviaries did not differ in any characteristic (size, exposition, or any biotic or abiotic parameter measured). Differently coloured pigeons 
may display different levels of expression of genes involved in the HPA axis activity in relation to environmental factors (either under captive or natural conditions). These factors may involve peri-natal exposure to corticosterone which has profound organizational effects on the HPA axis that shape stress response later in life (Love \& Williams 2008a; Love \& Williams 2008b; Wada et al. 2009). Corticosterone levels in developing birds primarily depend on maternal condition, nest-site characteristics and parental provisioning, all of these factors being likely affected by the level of urbanization of habitats (Crino et al. 2011, Bonier 2012). An interacting effect of melanic colouration with environment on the level of melanocortins has been well identified in tawny owls Strix aluco. In this species, the level of POMC-gene expression, as reflected by the circulating levels of POMC prohormone, as well as the level of gene expression of convertase enzyme $P C 1 / 3$ which cleaves POMC prohormone to obtain $\mathrm{ACTH}$, covary with the degree of melanic colouration under favorable conditions (Roulin et al. 2011; Emaresi et al. 2013). By contrast, in birds experiencing natural or experimentally-induced higher levels of stress, no colour-specific difference is detected potentially leading to up- and down-regulation of melanocortins acting on the HPA axis activity depending on conditions (Noguchi et al. 2006; Roulin et al. 2011). Whether variation in stress-induced corticosterone levels is linked to those of POMC-gene expression in feral pigeons remains to be tested. Finally among-population variation in stress response could be due to some genetic variation between the rural and the center-urbanized populations, independently of the colour phenotype and genetic underpinning. Indeed, important genetic variation exists between $C$. livia populations, for instance in the allele frequencies of numerous polymorphic proteins (Johnston \& Janiga, 1995). Such variations are notably measured between domestic and feral populations (Johnston \& Janiga, 1995). In our study, it is likely that rural pigeons are genetically closer to domestic lines than are the center- 
urbanized pigeons. Such a possibility requires future investigations examining the relationship between the genetic transmission of stress response and that of plumage coloration.

Alternatively, our results may reflect genetically-based, colour-specific divergences in stress response between differently urbanized populations due to selective forces associated with the urban environment. Such divergence despite the relatively recent history of urban colonization in feral pigeons would imply that evolutionary processes act quickly to shape the corticosterone response to stress, as also suggested in other bird species (Partecke et al. 2006; Angelier et al. 2011; Atwell et al. 2012). Rationales for strong selection on stress response is that it is genetically determined and heritable (Evans et al. 2006; Jenkins et al. 2014) and it has important fitness consequences (Breuner et al. 2008). Among the possible mechanisms of inheritance of stress response in polymorphic species, a role for imprinting on the genes coding for the receptors to regulate the HPA axis has been proposed (Almasi et al. 2010; Chong et al. 2007). Such genomic imprinting would occur in darker individuals and impair under some circumstances the pleiotropically-mediated genetic association between stress response and melanin-based colouration (Almasi et al. 2010). A similar mechanism may operate in dark feral pigeons established in highly urbanized areas, potentially conferring offspring with selective advantages as imprinted genes are targeted by selection and allow for rapid adaptive evolution (Danchin et al. 2011). So far, two studies have examined the genetic underpinning of differences in stress responses between differently urbanized populations of birds. Both studies found that urban birds raised in a common garden showed an attenuated corticosterone response to a 30-min restaint stress when compared with their wildland counterparts, the difference between corticosterone levels being highly comparable to that observed in dark feral pigeons (mean stress-induced corticosterone levels in less urbanized versus more urbanized populations: European blackbirds Turdus merula : 30 versus 15 ng.ml${ }^{1}$, Partecke et al. 2006; dark-eyed junco Junco hyemalis : 20 versus 12 ng.ml ${ }^{-1}$, Atwell et al. 
2012; feral pigeons: 23 versus $10 \mathrm{ng} \cdot \mathrm{ml}^{-1}$, this study). Thus our findings further extend the idea of urban selective pressures driving genetically-determined attenuated HPA responsiveness. This hypothesis should be further examined using replicates of habitats for each level of urbanization.

Independently of their exact underpinnings, a fundamental aspect of our results is that variation in stress response across different environmental conditions was observed in dark, but not in pale pigeons. This suggests that the genetic basis of stress response in darker pigeons allows for a greater plasticity or flexibility to environmental conditions (genotype-byenvironment effect) and/or is more easily targeted by selection. Jacquin et al. (2013a) recently showed that feral pigeons are darker in more urbanized areas of the Parisian agglomeration despite important gene flux between populations (Jacob, Prévot-Julliard and Baudry, unpublished), suggesting strong effect of selection on plumage colouration (Kawecki and Ebert 2004, Antoniazza et al. 2010). Whether any modulation of the HPA responsiveness accounts for some processes of local adaptation in dark pigeons requires extended field studies measuring the relation between stress physiology and fitness (reproductive success and survival) in differently coloured and differently urbanized individuals. The precise urban selective pressures involved in such local adaptation remain unknown, but may involve any factor associated with urban environments including trace metals (Chatelain et al. 2014) and human presence (Møller 2008).

Another important finding is that the covariation between melanin-based colouration and stress-induced corticosterone levels was observed in rural pigeons but not in more urbanized ones. This result opens the possibility that the genetic, pleiotropically-mediated association between colouration and stress response may be disrupted for some reasons and under some circumstances, resulting in the coexistence of alternative stress responses in some populations with plumage colour variation, but not in others. Theoretical models predict that 
the instability of environment is a potent selective mechanisms explaining individual variations in stress coping styles within populations (Dingemanse et al. 2004, Dingemanse \& Réale 2005; Carere et al. 2010) and more generally, that distinct personalities should emerge only under moderately favourable ecological conditions (i.e. under neither unfavourable nor highly favourable conditions; Luttbeg \& Sih 2010). Our results support the above predictions as the coexistence of colour-specific stress responses occurs in rural but not in urbanized areas which are characterized by a hampering of environmental variability (e.g. the seasonality of resource availability and climate) and likely constitute highly favourable ecological conditions for feral pigeons (Sacchi et al. 2002; Shochat et al. 2006). Another selective factor on the diversity of coping styles is the relative frequency of occurrence of similarly or differently behaving individuals (Wolf \& McNamara 2012), which likely varies between differently urbanized populations of feral pigeons (Jacquin et al. 2013b). We are aware that measuring stress response only once within individuals and only in captive birds limits the inferences that can be made, both with respect to the repeatability and the generalization under natural conditions. However, our results suggest that habitats along rural-urban gradient are potentially good candidates for alternative selective regimes acting on stress coping styles and more generally personalities. This hypothesis has already been partially validated by recent studies in birds (Evans et al. 2010; Atwell et al. 2012; Bokony et al. 2012; Miranda et al. 2013; Mueller et al. 2013) and humans (Malan et al. 2012). Research efforts are now needed towards the measurements of suites of behavioural and physiological traits along the proactive-reactive coping style axis in urban versus rural populations of pigeons and other species with plumage colour variation.

To conclude, we show that in a bird species with plumage colour variation, the degree of melanin-based colouration is associated with the ability to modulate stress response as a function of environmental conditions. The extent to which phenotypic adjustments, 
517 (epi)genetic divergences and the interaction between both processes explain differences in 518 colour-specific stress responses across environmental conditions requires further studies. The 519 issue could be addressed using common garden studies examining the reaction norms on 520 corticosterone release in differently coloured individuals from distinct habitats. Whatever the 521 exact cause of variation, the changes in stress response across environments being likely 522 genetically associated with colouration provides promising perspectives for the evolvability of 523 the HPA-axis in species with plumage colour variation. Thus our results suggest the 524 suitability of biological models with melanin-based variation in questioning the evolvability 525 of the HPA axis and perhaps that of copying styles under different selective regimes, at a time 526 when flourishing theoretical models explaining the evolution of personalities urgently call for 527 empirical tests (Wolf et al. 2007; Dingemanse \& Wolf 2010; Dingemanse et al. 2010; Luttbeg \& Sih 2010; Carere et al. 2010; Wolf \& McNamara 2012). 


\section{Acknowledgements}

We thank Thomas Charachon from the Mairie de Paris and Adeline Loyau from the Ferme Traditionnelle Educative de Mandres-Les-Roses for logistic support during the captures. We are grateful to the CEREEP station, Philippe Lenouvel and Aurélien Mouton for great help at different stages of this study. This work was supported by a grant from the Centre National de la Recherche Scientifique and from Université Pierre et Marie Curie. The experiments comply with the current French laws. All experiments were conducted under the authorization of the "Direction Départementale des Services Vétérinaires de Seine-et-Marne" (authorization $\left.\mathrm{N}^{\circ} 77-07\right)$.

All applicable international, national, and/or institutional guidelines for the care and use of animals were followed.

This article does not contain any studies with human participants performed by any of the authors.

Informed consent was obtained from all individual participants included in the study.

\section{Conflicts of interest}

The authors declare that they have no conflict of interest. 


\section{Literature cited}

Addis E.A., Jason E.D., Brooks, E.M. \& Wingfield, J.C. (2011). Variation in circulating corticosterone levels is associated with altitudinal range expansion in a passerine bird. Oecologia, 167: 369-378.

Almasi B., Jenni L., Jenni-Eiermann S. \& Roulin A. (2010). Regulation of stress response is heritable and functionally linked to melanin-based coloration. Journal of Evolutionary Biology, 23: 987-996.

Almasi B., Roulin A., Jenni-Eiermann S., Breuner C.W. \& Jenni L. (2009). Regulation of free corticosterone and CBG capacity under different environmental conditions in altricial nestlings. General and Comparative Endocrinology, 164: 117-124.

Almasi B., Roulin A., Korner-Nievergelt F., Jenni-Eiermann S. \& Jenni. L. (2012). Coloration signals the ability to cope with elevated stress hormones: effects of corticosterone on growth of barn owls are associated with melanism. Journal of Evolutionary Biology, 25: 1189-1199.

Angelier F., Ballentine B., Holberton R.L., Marra P.P. \& Greenberg R. (2011). What drives variation in the corticosterone stress response between subspecies? A common garden experiment of swamp sparrows (Melospiza georgiana). Journal of Evolutionary Biology, 24: 1274-1283.

Antoniazza S., Burri R., Fumagalli L., Goudet J. \& Roulin A. (2010). Local adaptation maintains clinal variation in melanin-based coloration of European barn owls (Tyto alba). Evolution, 64: 1944-1954.

Atwell J.W., Cardoso G.C., Whittaker D.J., Campbell-Nelson S., Robertson K.W. \& Ketterson E.D. (2012). Boldness behavior and stress physiology in a novel urban environment suggest rapid correlated evolutionary adaptation. Behavioral Ecology, 23: 960-969. 
571 Syndromes in Differently Urbanized Populations of House Sparrows (Passer domesticus).

572 PLoS One: 7 (5): e36639.

Bonier F. (2012). Hormones in the city: endocrine ecology of urban birds. Hormones and Behavior, 61: 763-772.

Breuner C.W., Greenberg A.L. \& Wingfield J.C. (1998). Noninvasive corticosterone treatment rapidly increases activity in Gambel's white-crowned sparrows (Zonotrichia leucophrys gambelii). General and Comparative Endocrinology, 111: 386-394.

Breuner C.W., Wingfield J.C. \& Romero L.M. (1999). Diel rhythms of basal and stressinduced corticosterone in a wild, seasonal vertebrate, Gambel's white-crowned sparrow. Journal of Experimental Zoology, 284: 334-342.

Breuner C.W., Patterson S.H. \& Hahn T.P. (2008). In search of relationships between the acute adrenocortical response and fitness. General and Comparative Endocrinology, $157: 288-295$.

Burnham K.P. \& Anderson D.R. (2002) Model selection and multimodel inference: a practical information-theoretic approach. Springer, New York.

Busch D.S. \& Hayward L.S. (2009). Stress in a conservation context: A discussion of glucocorticoid actions and how levels change with conservation-relevant variables. Biological Conservation, 142: 2844-2853.

Carere C., Caramaschi D. \& Fawcett T.W. (2010). Covariation between personalities and individual differences in coping with stress: converging evidence and hypotheses. Current Zoology, 56: 728-740.

Chatelain M., Gasparini J., Jacquin L. \& Frantz A. (2014). The adaptive function of melanin-based plumage coloration to trace metals. Biology Letters, 10: 20140164. 
Chong S.Y., Vickaryous N., Ashe A., Zamudio N., Youngson N., Hemley S., Stopka T., Skoultchi A., Matthews J., Scott H.S., de Kretser D., O’Bryan M., Blewitt M. \& Whitelaw E. (2007). Modifiers of epigenetic reprogramming show paternal effects in the mouse. Nat. Genet., 39: 614-622.

Cockrem J.F. (2007). Stress, corticosterone responses and avian personalities. Journal of Ornithology, 148: S169-S178.

Cockrem J.F., Potter M.A. \& Candy E.J. (2006). Corticosterone in relation to body mass in Adelie penguins (Pygoscelis adeliae) affected by unusual sea ice conditions at Ross Island, Antarctica. General and Comparative Endocrinology, 149: 244-252.

Cockrem J.F., Barrett D.P., Candy E.J. \& Potter M.A. (2009). Corticosterone responses in birds: Individual variation and repeatability in Adelie penguins (Pygoscelis adeliae) and other species, and the use of power analysis to determine sample sizes. General and Comparative Endocrinology, 163: 158-168.

Corbel H., Geiger S. \& Groscolas R. (2010). Preparing to fledge: the adrenocortical and metabolic responses to stress in king penguin chicks. Functional Ecology: 24, 82-92.

Crespi E.J., Williams T.D., Jessop T.S. \& Delehanty B. (2013). Life history and the ecology of stress: how do glucocorticoid hormones influence life-history variation in animals? Functional Ecology, 27: 93-106.

Crino O.L., Klaassen Van Oorschot B., Johnson E.E., Malisch J.L. \& Breuner C.W. (2011). Proximity to a high traffic road: Glucocorticoid and life history consequences for nestling white-crowned sparrows. General and Comparative Endocrinology, 173: 323-332.

Cyr N.E. \& Romero L.M. (2009). Identifying hormonal habituation in field studies of stress. General and Comparative Endocrinology, 161: 295-303. 

(2011). Beyond DNA: integrating inclusive inheritance into an extended theory of evolution.

619

620

621

622

623

624

625

626

627

628

629

630

631

632

633

634

635

636

637

638

639

640

Nat. Rev. Genet., 12: 475-486.

Daynes R.A., Robertson B.A., Cho B.H., Burnham D.K. \& Newton R. (1987) Alphamelanocyte-stimulating hormone exhibits target cell selectivity in its capacity to affect interleukin 1-inducible responses in vivo and in vitro. Journal of Immunolology, 139: 103109.

Dhabhar F.S. \& McEwen B.S. (1997). Acute stress enhances while chronic stress suppresses cell-mediated immunity in vivo: a potential role for leukocyte trafficking. Brain Behavior and Immunity, 11: 286-306.

Dickens M.J., Kristen A., Earle L. \& Romero L.M. (2009). Initial transference of wild birds to captivity alters stress physiology. General and Comparative Endocrinology, 160: 7683.

Dingemanse N.J., Both C., Drent P.J., van Oers K. \& van Noordwijk A.J. (2002). Repeatability and heritability of exploratory behaviour in wild great tits. Anim. Behav., 64: 929-937.

Dingemanse N.J. \& Réale D. (2005). Natural selection and animal personality. Behaviour, 142: 1159-1184.

Dingemanse N.J. \& Wolf M. (2010). Recent models for adaptive personality differences: a review. Philosopical Transactions of the Royal Society B-Biological Sciences, 365: $3947-3958$.

Dingemanse N.J., Both C., van Noordwijk A.J., Rutten A.L. \& Drent P.J. (2003). Natal dispersal and personalities in great tits (Parus major). Proceedings of the Royal Society BBiological Sciences, 270: 741-747. 

of avian personalities in a fluctuating environment. Proceedings of the Royal Society B-

643

644

645

646

647

648

649

650

651

652

653

654

655

656

657

658

659

660

661

662

663

664

Biological Sciences, 271: 847-852.

Dingemanse N.J., Kazem A.J.N., Réale D. \& Wright J. (2010). Behavioural reaction norms: animal personality meets individual plasticity. Trends in Ecology \& Evolution, 25: 8189.

Dreiss A.N., Antoniazza S., Burri R., Fumagalli L., Sonnay C., Frey, C. Goudet J. \& Roulin A. (2012). Local adaptation and matching habitat choice in female barn owls with respect to melanic coloration. Journal of Evolutionary Biology, 25: 103-114.

Drent, P.J., van Oers K. \& van Noordwijk A.J. (2003). Realized heritability of personalities in the great tit (Parus major). Proc. R. Soc. Lond. B, 270: 45-51.

van Oers, K. et al. (2005) Contribution of genetics to the study of animal personalities: a review of case studies. Behaviour 142, 1185-1206.

Ducrest A.L., Keller L. \& Roulin A. (2008). Pleiotropy in the melanocortin system, coloration and behavioural syndromes. Trends in Ecology and Evolution, 23: 502-510.

Emaresi G., Ducrest A.L., Bize P., Richter H., Simon C. \& Roulin A. (2013). Pleiotropy in the melanocortin system: expression levels of this system are associated with melanogenesis and pigmentation in the tawny owl (Strix aluco). Molecular Ecology, 22: 4915-4930.

Evans M.R., Roberts M.L., Buchanan K.L. \& Goldsmith A.R. (2006). Heritability of corticosterone response and changes in life history traits during selection in the zebra finch. Journal of Evolutionary Biology, 19: 343-352.

Evans K.L. (2010). Individual species and urbanization. In Urban ecology. (ed Gaston, K.J), pp. 53-87. Cambridge, UK: Cambridge University Press. 

trait reflects environmental growth conditions of nestling male Eurasian kestrels.

667

668

669

670

671

672

673

674

675

676

677

678

679

680

681

682

683

684

685

686

687

688

689

Evolutionary Ecology, 21:157-171.

Frantz A., Pottier M.A., Karimi B., Corbel H., Aubry E., Haussy C., Gasparini J. \& Castrec-Rouelle M. (2012). Contrasting levels of heavy metals in the feathers of urban pigeons from close habitats suggest limited movements at a restricted scale. Environmental Pollution, 168: 23-28.

Giraudeau M. \& McGraw K.J. (2014). Physiological correlated of urbanization in a desert songbird. Integrative and Comparative Biology, 54 : 622-632.

Griffiths R., Double M.C., Orr K. \& Dawson R.J.G. (1998). A DNA test to sex most birds. Molecular Ecology, 7: 1071-1075.

Haase E., Ito S., Sell A. \& Wakamatsu K. (1992). Melanin concentrations in feathers from wild and domestic pigeons. Journal of Heredity, 83: 64-67.

Jacquin L., Lenouvel P., Haussy C., Ducatez S. \& Gasparini J. (2011). Melanin-based coloration is related to parasite intensity and cellular immune response in an urban free living bird: the feral pigeon Columba livia. Journal of Avian Biology, 42: 11-15.

Jacquin L., Récapet C., Bouche P., Leboucher G. \& Gasparini J. (2012). Melanin-based coloration reflects alternative strategies to cope with food limitation in pigeons. Behavioral Ecology, 23: 907-915.

Jacquin L., Haussy C., Bertin C., Laroucau K. \& Gasparini J. (2013a). Darker female pigeons transmit more specific antibodies to their eggs than do paler ones. Biological Journal of the Linnean Society, 108: 647-657.

Jacquin L., Récapet C., Prévot-Julliard A.C., Leboucher G., Lenouvel P., Erin N., Frantz A., Corbel H., Gasparini J. (2013b). A potential role for parasites in the maintenance of bird color polymorphism in cities. Oecologia, 173: 1089-1099. 
Jenkins B.R., Vitousek M.N., Hubbard J.K. \& Safran R.J. (2014). An experimental analysis of the heritability of variation in glucocorticoid concentrations in a wild avian population. Proc. R. Soc. Lond., 281: 0141302. http://dx.doi.org/10.1098/rspb.2014.1302 Johnston R.F. \& Janiga M. 1995. Feral pigeons. (eds). Oxford University Press, Oxford.

Kawecki T.J. and Ebert D. (2004). Conceptual issues in local adaptation. Ecology Letters, 7: 1225-1241.

Kittilsen S., Schjolden J., Beitnes-Johansen I., Shaw J.C., Pottinger T.G., Sorensen C., Braastad B.O., Bakken M. \& Overli O. (2009). Melanin-based skin spots reflect stress responsiveness in salmonid fish. Hormones and Behavior, 56: 292-298.

Koolhaas J.M., Korte S.M., De Boer S.F., Van Der Vegt B.J., Van Reenen C.G., Hopster H., De Jong I.C., Ruis M.A. \& Blokhuis H.J. (1999). Coping styles in animals: current status in behavior and stress-physiology. Neuroscience \& Biobehavioral Reviews, 23: 925-35.

Liker A., Papp Z., Bokony V. \& Lendvai A. Z. 2008. Lean birds in the city: body size and condition of house sparrows along the urbanization gradient. Journal of Animal Ecology, 77: 789-795.

Luttbeg B. \& Sih A. (2010). Risk, resources and state- dependent adaptive behavioural syndromes. Philosophical Transactions of the Royal Society B-Biological Sciences, 365: 3977-3990.

Love O.P. \& Williams T.D. (2008a). Plasticity in the adrenocortical response of a freeliving vertebrate: The role of pre- and post-natal developmental stress. Hormones and Behavior, 54: 496-505. 
Love O.P. \& Williams T.D. (2008b). The adaptive value of stress-induced phenotypes:

714

715

716

717

718

719

720

721

722

Effects of maternally derived corticosterone on sex-biased investment, cost of reproduction, and maternal fitness. The American Naturalist, 172: E135-E149.

Malan L., Hamer M., Reimann M., Huisman H., Van Rooyen J., Schutte A., Schutte R., Potgieter J., Wissing M., Steyn F., Seedat Y. \& Malan N. (2012). Defensive coping, urbanization, and neuroendocrine function in Black Africans: the THUSA study. Psychophysiology, 49: 807-814.

McDonnell M.J. \& Hahs A.K. (2009). Comparative ecology of cities and towns: past, present and future. In Ecology of cities and towns: a comparative approach (eds M.J. McDonnell, A.K. Hahs, J. Breuste), pp. 71-89. Cambridge, UK: Cambridge University Press. McEwen B. \& Wingfield J. (2003). The concept of allostasis in biology and biomedicine. Horm. Behav., 43: 2-15.

McGuill, M.W. \& Rowan, A.N. 1989. Biological effects of blood loss: implications for sampling volumes and techniques. ILAR News, 31: 5-18.

Miranda A.C., Schielzeth H., Sonntag T. \& Partecke J. (2013). Urbanization and its effects on personality traits: a result of microevolution or phenotypic plasticity? Global Change Biology, 19: 2634-2644.

Møller A.P. (2008). Flight distance of urban birds, predation, and selection for urban life. Behavioral Ecology and Sociobiology, 63: 63-75.

Morgan C., Thomas R.E. \& Cone R.D. (2004). Melanocortin-5 receptor deficiency promotes defensive behavior in male mice. Hormones and Behavior, 45: 58-63.

Mueller J.C., Partecke J., Hatchwell B.J., Gaston K.J. \& Evans K.L. (2013). Candidate gene polymorphisms for behavioural adaptations during urbanization in blackbirds. Molecular Ecology, 22: 3629-3637. 
Mundy N.I. (2005). A window on the genetics of evolution: MC1R and plumage

colouration in birds. Proceedings of The Royal Society B: Biological Sciences, 272: 16331640.

Mundy N.I., Badcock N.S., Hart T., Scribner K., Janssen K. \& Nadeau N.J. (2004).

Conserved genetic basis of a quantitative plumage trait involved in mate choice. Science, 303: $1870-1873$.

Niemelä J., Breuste J.H., Guntenspergen G., McIntyre N.E., Elmqvist T. \& James P. (2011). Urban Ecology: Patterns, Processes, and Applications. 392 pages. Oxford University Press.

Noguchi T., Makino S., Maruyama H. \& Hashimoto K. (2006). Regulation of proopiomelanocortin gene transcription during single and repeated immobilization stress. Neuroendocrinology, 84: 21-30.

O'Reilly, K.M. \& Wingfield, J.C. (2001). Ecological factors underlying the adrenocortical response to capture stress in arctic-breeding shorebirds. General and Comparative Endocrinology, 124: 1-11.

Partecke J., Schwabl I. \& Gwinner E. (2006). Stress and the city: urbanization and its effects on the stress physiology in European Blackbirds. Ecology, 87: 1945-1952.

Pascual J.A., Fryday S.L. \& Hart A.D.M. (1999). Effects of Food Restriction on Food Avoidance and Risk of Acute Poisoning of Captive Feral Pigeons from Fonofos-Treated Seeds. Archives of Environmental Contamination and Toxicology, 37: 115-124.

Pryke S.R., Astheimer L.B., Buttemer W.A. \& Griffith S.C. (2007). Frequencydependent physiological trade-offs between competing colour morphs. Biology Letters, 3: 494-497.

Racca S., Spaccamiglio A., Esculapio P., Abbadessa G., Cangemi L., DiCarlo F. \& Portaleone P. (2005). Effects of swim stress and [alpha]-MSH acute pre-treatment on brain 5- 
HT transporter and corticosterone receptor. Pharmacology Biochemistry \& Behavior, 81: 894900.

Raouf S.A., Smith L.C., Brown M.B., Wingfield J.C. \& Brown C.R. (2006). Glucocorticoid hormone levels increase with group size and parasite load in cliff swallows. Animal Behaviour, 71: 39-48.

Rensel M.A. \& Schoech S.J. (2011). Repeatability of baseline and stress-induced corticosterone levels across early life stages in the Florida scrub-jay (Aphelocoma coerulescens). Hormones and Behavior, 59: 497-502.

Romero L.M. (2002). Seasonal changes in plasma glucocorticoid concentrations in freeliving vertebrates, General and Comparative Endocrinology, 128: 1-24.

Romero L.M., Ramenofsky M. \& Wingfield J.C. (1997). Season and migration alters the corticosterone response to capture and handling in an arctic migrant, the white-crowned sparrow (Zonotrichia leucophrys gambelii). Comparative Biochemistry and Physiology Part C: Pharmacology, Toxicology and Endocrinology, 116: 171-777.

Romero L.M. \& Wingfield J.C. (1999). Alterations in hypothalamic-pituitary-adrenal function associated with captivity in Gambel's white-crowned sparrows (Zonotrichia leucophrys gambelii). Journal of Comparative Physiology Part B: Biochemistry and Molecular Biology, 122: 13-20.

Romero L.M. \& Wingfield J.C. (2001). Regulation of the hypothalamic-pituitaryadrenal axis in free-living pigeons. Journal of Comparative Physiology Part B: Biochemistry and Molecular Biology, 171: 231-235.

Roulin A., Emaresi G., Bize P., Gasparini J., Piault R. \& Ducrest A.L. (2011). Pale and dark reddish melanic tawny owls differentially regulate the level of blood circulating POMC prohormone in relation to environmental conditions. Oecologia, 166: 913-921. 
Roulin A., Gasparini J., Bize P., Ritschard M. \& Richner H. (2008). Melanin-based

787

788

789

790

791

792

793

794

795

796

797

798

799

800

801

802

803

804

805

806

807

808

809

colorations signal strategies to cope with poor and rich environments. Behavioral Ecology and Sociobiology, 62: 507-519.

Sacchi R., Gentilli A., Razzetti E. \& Barbieri F. (2002). Effects of building features on density and flock distribution of feral pigeons Columba livia var. domestica in an urban environment. Canadian Journal of Zoology, 80:48-54.

Sapolsky R.M., Romero L.M. \& Munck A.U. (2000). How do glucocorticoids Influence stress responses? Integrating permissive, suppressive, stimulatory, and preparative actions. Endocrine Reviews, 21: 55-89.

Satterlee D.G. \& Johnson W.A. (1988). Selection of japanese quail for contrasting blood corticosterone response to immobilization. Poultry Science, 67: 25-32.

Schoech S.J., Bowman R., Bridge E.S. \& Boughtona R.K. (2007). Baseline and acute levels of corticosterone in Florida Scrub-Jays (Aphelocoma coerulescens): Effects of food supplementation, suburban habitat, and year. General and Comparative Endocrinology, 154: 150-160.

Schoech S. (2006). Food availability and timing of reproduction: Are high-latitude species less flexible in responding to supplementary cues? Journal of Ornithology, 147: 7070.

Senar J. C. (1999). Plumage coloration as a signal of social status. Proceedings of the International Ornithological Congress, 22: 1669-1686.

Shochat E., Warren P.C., Faeth S.H. \& McIntyre N.E. (2006). From patterns to emerging processes in mechanistic urban ecology. Trends in Ecology and Evolution, 21:186191

Silverin B. (1998). Stress responses in birds. Poultry and Avian Biology Reviews, 9: 
Sol D. (2008). Artificial selection, naturalization, and fitness: Darwin's pigeons revisited. Biological Journal of the Linnean Society, 93: 657-665.

Sol D., Jovani R. \& Torres J. (2000). Geographical variation in blood parasites in feral pigeons: the role of vectors. Ecography, 23; 307-314.

Stier K.S., Almasi B., Gasparini J., Piault R., Roulin A. \& L. Jenni. (2009). Effects of corticosterone on innate and humoral immune functions and oxidative stress in barn owl nestlings. The Journal of Experimental Biology, 212: 2085-2091.

Theron E., Hawkins K., Bermingham E., Ricklefs R. \& Mundy N. I. (2001). The molecular basis of an avian plumage polymorphism in the wild: a point mutation in the melanocortin-1 receptor is perfectly associated with melanism in the bananaquit (Coereba flaveola). Current Biology, 11: 550-557.

Thiel D., Jenni-Eiermann S., Braunisch V., Palme R. \& Jenni L. (2008). Ski tourism affects habitat use and evokes a physiological stress response in capercaillie Tetrao urogallus: a new methodological approach. Journal of Applied Ecology, 45: 845-853.

Wada H., Salvante K.G., Wagner E., Williams T.D. \& Breuner C.W. (2009). Ontogeny and Individual Variation in the Adrenocortical Response of Zebra Finch (Taeniopygia guttata) Nestlings. Physiological and Biochemical Zoology, 82: 325-331.

Walker, B.G., Boersma, P.D. \& Wingfield, J.C. (2006). Habituation of adult magellanic penguins to human visitation as expressed through behavior and corticosterone secretion. Conservation Biology, 20: 146-154.

Williams C.T., Kitaysky A.S., Kettle A.B. \& Buck C.L. (2008). Corticosterone levels vary with breeding stage, body condition index, and reproductive performance in tufted puffins. General and Comparative Endocrinology, 158: 29-35.

Wingfield J.C., Smith J.P. \& Farner D.S. (1982). Endocrine responses of white-crowned sparrows to environmental stress. Condor, 84: 399-409. 

personalities. Nature, 450: E5-E6. evolution. Trends in Ecology and Evolution, 27: 452-461. 
Table 1

843 Characteristics of habitats

\begin{tabular}{|c|c|c|c|c|c|c|}
\hline \multirow[b]{2}{*}{ Site } & \multirow[b]{2}{*}{$\begin{array}{l}\text { Capture } \\
\text { date }\end{array}$} & \multirow[b]{2}{*}{ Site name } & \multirow[b]{2}{*}{$\begin{array}{l}\text { (district } \\
\text { number) }\end{array}$} & \multirow[b]{2}{*}{ GPS coordinates } & \multicolumn{2}{|l|}{ Urbanization } \\
\hline & & & & & $\begin{array}{c}\text { rate }(\% \\
\text { construced } \\
\text { area })\end{array}$ & $\begin{array}{l}\text { Habitat } \\
\text { type }\end{array}$ \\
\hline $\mathrm{A}$ & $02 / 03 / 2010$ & $\begin{array}{l}\text { Porte Saint- } \\
\text { Denis }\end{array}$ & Paris $(\mathrm{X})$ & $\begin{array}{c}48^{\circ} 52^{\prime} 11.194^{\prime \prime} \mathrm{N} \\
2^{\circ} 21^{\prime} 9.342^{\prime \prime} \mathrm{E}\end{array}$ & 97 & $\begin{array}{l}\text { Urban } \\
\text { center }\end{array}$ \\
\hline B & $04 / 02 / 2010$ & $\begin{array}{l}\text { Arènes de } \\
\text { Lutèce }\end{array}$ & Paris (V) & $\begin{array}{c}48^{\circ} 50^{\prime} 42.269^{\prime \prime} \mathrm{N} \\
2^{\circ} 21^{\prime} 8.614^{\prime \prime} \mathrm{E}\end{array}$ & 79 & $\begin{array}{l}\text { Urban } \\
\text { park }\end{array}$ \\
\hline $\mathrm{C}$ & $11 / 02 / 2010$ & $\begin{array}{l}\text { Mandres- } \\
\text { Les-Roses }\end{array}$ & $\begin{array}{c}\text { Mandres- } \\
\text { Les-Roses } \\
\text { (94) }\end{array}$ & $\begin{array}{l}48^{\circ} 42^{\prime} 23.536^{\prime} \mathrm{N} \\
2^{\circ} 33^{\prime} 15.557^{\prime \prime} \mathrm{E}\end{array}$ & 47 & Rural farm \\
\hline
\end{tabular}


Table 2

846 Effects of blood sampling time, plumage colour type and habitat on corticosterone levels $(n=$

847164 measurements $)$ along restraint stress in feral pigeons $(n=41$ pigeons $)$.

848

\begin{tabular}{lccc}
\hline Effect & $d f$ & $F$ & $P$ \\
\hline Sex & 1,34 & 5.52 & $\mathbf{0 . 0 3}$ \\
Sampling time & 3,105 & 64.06 & $<\mathbf{0 . 0 0 1}$ \\
Colour type & 1,34 & 3.96 & 0.05 \\
Habitat & 2,34 & 1.37 & 0.27 \\
Sampling time $\times$ Colour type & 3,105 & 2.40 & 0.07 \\
Sampling time $\times$ Habitat & 6,105 & 0.76 & 0.61 \\
Colour type $\times$ Habitat & 2,34 & 3.01 & 0.06 \\
Sampling time $\times$ Colour type $\times$ Habitat & 6,105 & 2.53 & $\mathbf{0 . 0 3}$ \\
\hline Significant $P-v a l u e s(<0.05)$ are in bold & & & \\
\hline
\end{tabular}


852 Fig. 1 Corticosterone levels (CORT) measured at $3 \mathrm{~min}\left(1^{\text {st }}\right.$ blood sample, baselines), $10 \mathrm{~min}$ 853 ( $2^{\text {nd }}$ blood sample), $20 \mathrm{~min}\left(3^{\text {rd }}\right.$ blood sample $)$ and $30 \mathrm{~min}\left(4^{\text {th }}\right.$ blood sample $)$ after capture in 854 pale (white circles) and dark (black circles) restrained feral pigeons from 3 habitats (urban 855 center: pale, $n=10$, dark, $n=5$; urban park: pale, $n=5$, dark, $n=8$; rural area: pale, $n=7$, 856 dark, $n=6$ ). Values are means \pm SE. Different superscript letters represent significant 857 differences $(P<0.05)$ between habitats within each colour type morph and each sampling 858 time following post hoc tests. The letters can not be compared within habitats. Asterisks 859 represent significant differences $(P<0.05)$ between colour type morphs within each habitat 860 following post hoc tests

862 Fig. 2 Relation between stress-induced corticosterone levels (CORT) measured at $30 \mathrm{~min}$ 863 after captures and black colouration scores in feral pigeons from 3 sites corresponding to a) 864 urban center $(\mathrm{N}=15), \mathrm{b})$ urban park $(\mathrm{N}=13)$, and c) rural area $(\mathrm{N}=15)$. The line is for the 865 significant regression of CORT on colouration scores $(P=0.021$, see results). 